\title{
Determination of sedimentation rates and absorption coefficient of insoluble metal carbonates
}

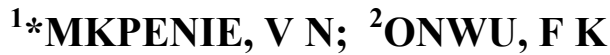 \\ ${ }^{1}$ Department of Chemistry, University of Uyo, Uyo, P. M. B. 1017,Uyo, Akwa Ibom State, Nigeria. \\ ${ }^{2}$ Department 'of Industrial Chemistry, Ebonyi State University, Abakaliki, P. M. B. 53, Ebonyi State, Nigeria
}

\begin{abstract}
Studies on the sedimentation rates of insoluble metal carbonates showed that $\mathrm{Zn}^{2+}$ has a higher sedimentation rate of $5.10 \times 10^{-2} \mathrm{~s}^{-1}$ while $\mathrm{Ni}^{2+}$ has the lowest sedimentation rates of $1.10 \times 10^{-3}$. The rate of sedimentation of the metal carbonates decreased in the order: $\mathrm{Zn}^{2+}>\mathrm{Cd}^{2+}>\mathrm{Cu}^{2+}>\mathrm{Co}^{2+}>\mathrm{Ni}^{2+}$. The order showed a decrease in the density of the carbonates and also correlated with the decrease in the mass (and particle) absorption coefficient of the metal carbonates. @jJASEM
\end{abstract}

Many chemical reactions form separable solid phase within a liquid medium. The solid phase particles fall to the bottom of the liquid under gravity as sediments. Sedimentation is defined as the process in which heavy particles settle toward the foot of a column of solution in a gravitational field (Atkins, 1994). Sedimentation readily occurs when particle size is above $1000 \mathrm{~nm}$. Particles below $1000 \mathrm{~nm}$ exist as colloids in solution (Shaw, 1992). The sedimenting particles can be monitored to determine sedimentation rates, sedimentation constants and sedimentation orders. These sedimentation parameters have been determined for the insoluble transition metal hydroxide (Essien, 1992). Sedimentation rate is a fundamental dynamic property which depends on density, size and shape of the particles. These particles have pores that can absorb radiation. Gamma rays have been used to study the absorption coefficients of cobalt(II) insoluble compounds (Essien and Ekpe, 1998), densities of marine sediments (Gerland and Villinger, 1995) and soil particle-size distribution (Vaz et al., 1992).

In this study, sedimentation rates of insoluble transition metal carbonates are determined. Gamma rays from ${ }^{60} \mathrm{Co}$ source are used to determine the absorption coefficient of these metal carbonates. The results obtained are used to investigate the functional relationship between sedimentation rate and absorption coefficient.

\section{MATERIALS AND METHODS}

All chemicals used were of analytical grade. These include $\mathrm{Na}_{2} \mathrm{CO}_{3}, \mathrm{Co}\left(\mathrm{NO}_{3}\right)_{2} \cdot 6 \mathrm{H}_{2} \mathrm{O}, \mathrm{CuC}\left(\mathrm{NO}_{3}\right)_{2} \cdot 3 \mathrm{H}_{2} \mathrm{O}$,
$\mathrm{NiCl}_{2} \cdot 6 \mathrm{H}_{2} \mathrm{O}, \mathrm{Zn}\left(\mathrm{NO}_{3}\right)_{2} \cdot 7 \mathrm{H}_{2} \mathrm{O}$ and $\mathrm{CdSO}_{4} \cdot 8 \mathrm{H}_{2} \mathrm{O}$. All preparations were carried out using distilled water.

Determination of sedimentation rates : The experimental procedure was similar to the one described earlier (Essien, 1992) and was modified as follows: $20 \mathrm{ml}$ of $0.1 \mathrm{M} \mathrm{Na}_{2} \mathrm{CO}_{3}$ was carefully added to $20 \mathrm{ml}$ of the metal salts $(0.2-0.01 \mathrm{M})$ in a $100 \mathrm{ml}$ measuring cylinder, stirred and allowed to stand. A stop watch was immediately started after stirring and the time taken for the precipitates to fall was recorded at various volumes. The rate of sedimentation was obtained from the slope of the plot of the change in volume of the sedimenting carbonates $(\Delta \mathrm{V})$ against time $(t)$. The precipitated carbonates were obtained according to equation (1) and the rate of sedimentation was expressed as shown in equation (2).

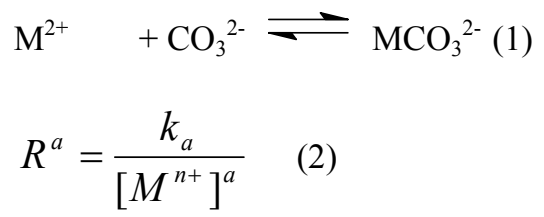

where: $R_{s}$ is the sedimentation rate; $k_{s}$ is the sedimentation rate constants $=\mathrm{k} /[\mathrm{A}]^{\mathrm{b}} ;\left[\mathrm{M}^{\mathrm{n}+}\right]$ is the concentration of the metal ion; $\mathrm{a}$ is sedimentation orders with respect to the metal ion. The sedimentation constant $\left(\mathrm{k}_{\mathrm{s}}\right)$ was deduced from the intercept while sedimentation order (a) was obtained from the slope of the plot of $\log \mathrm{R}_{\mathrm{s}}$ versus $\log \left[\mathrm{M}^{\mathrm{n}+}\right]$. 
Determination of absorption coefficient: The procedure used was described earlier (Essien and Ekpe, 1998). The set up comprised of a GM tube connected to a scalar/timer. The container was a graduated measuring cylinder which contained the precipitated insoluble metal carbonates. The liquid medium was removed by suction and the height of the precipitates was recorded as the sample thickness (d). The measuring cylinder was placed over ${ }^{60} \mathrm{Co}$ used as gamma-ray irradiation source. The count with the empty measuring cylinder was taken as $\mathrm{I}_{0}$ while the count with the sample was recorded as $\mathrm{I}_{\mathrm{t}}$. the counting was done for 10 minutes. The precipitates were finally oven-dried, weighed and their densities were determined by weighing and displacement method. The intensity of gamma radiation transmitted through the metal carbonates was express as given in equation (3).

$$
I_{t}=I_{o} e^{-\mu d}
$$

where: $I_{0}$ is the intensity of incident radiation; $I_{t}$ is the intensity of transmitted radiation; $\mu$ is the absorption coefficient; $d$ is the sample thickness; The absorption coefficient $(\mu)$ was obtained from the slope of the plot of In $\left(\mathrm{I}_{\mathrm{o}} / \mathrm{I}_{\mathrm{t}}\right)$ versus $\mathrm{d}$.

\section{RESULTS AND DISCUSSION}

The rate of sedimentation $\left(R_{s}\right)$ is found to decrease with increase in the concentration of the precipitating agents (Essien, 1992). The results for the sedimentation parameters and absorption coefficients obtained are presented in Table 1.

Table 1: Sedimentation Parameters and Absorption Coefficient of Metal Carbonates.

\begin{tabular}{ccccccc}
\hline $\mathrm{M}^{\mathrm{n}+}$ & $\begin{array}{l}\text { Sedimentation } \\
\text { Rate } \\
\mathrm{cm}^{3} \mathrm{~s}^{-1} \times 10^{-2}\end{array}$ & $\begin{array}{l}\text { Sedimentation } \\
\text { Order }\end{array}$ & $\begin{array}{l}\text { Sedimentation } \\
\text { Constants } \\
\mathrm{s}^{-1} \times 10^{-4}\end{array}$ & $\begin{array}{l}\text { Particle } \\
\text { Absorption } \\
\text { Coefficient } \\
\mathrm{cm}^{-1}\end{array}$ & $\begin{array}{l}\text { Determined } \\
\text { Density } \\
\mathrm{gcm}^{-3}\end{array}$ & $\begin{array}{l}\text { Mass } \\
\text { Absorption } \\
\text { Coefficient } \\
\mathrm{cm}^{2} \mathrm{~g}^{-1}\end{array}$ \\
\hline $\mathrm{Zn}^{2+}$ & 5.10 & 1.43 & 14.12 & $5.03 \times 10^{-2}$ & 1.382 & 0.0364 \\
$\mathrm{Cd}^{2+}$ & 4.17 & 0.82 & 8.40 & $3.36 \times 10^{-2}$ & 1.246 & 0.0270 \\
$\mathrm{Cu}^{2+}$ & 0.85 & 1.51 & 3.55 & $1.67 \times 10^{-2}$ & 0.929 & 0.0180 \\
$\mathrm{Co}^{2+}$ & 0.28 & 1.19 & 2.45 & $5.51 \times 10^{-3}$ & 0.375 & 0.0147 \\
$\mathrm{Ni}^{2+}$ & 0.11 & 1.76 & 0.16 & $3.97 \times 10^{-3}$ & 0.361 & 0.0110 \\
\hline
\end{tabular}

$\mathrm{Zn}^{2+}$ had the highest sedimentation rate constants, $14.12 \times 10^{-4}$ while nickel had lowest, $\quad 1.6 \times 10^{-5}$. There was a gradual increase in the rate of sedimentation which correlated well with increase in the density of the metal carbonates as depicted in this order: $\mathrm{Zn}^{2+}>\mathrm{Cd}^{2+}>\mathrm{Cu}^{2+}>\mathrm{Co}^{2+}>\mathrm{Ni}^{2+} \cdot \mathrm{Ni}^{2+}$ had a second order of sedimentation, $\mathrm{Zn}^{2+}$ and $\mathrm{Co}^{2+}$ had first order while that of $\mathrm{Cu}^{2+}$ and $\mathrm{Cd}^{2+}$ may be $3 / 2$ and 1 respectively.

The absorption of gamma radiation by the metal carbonate is shown in figure 1. Absorption of gamma radiation depends on factors such as density and size of the particle. High density particles absorb more radiation than low density particles (Lieser, 1997). Particles with larger size possess greater pore spaces and therefore absorb radiation more than small-sized particles (Gardner et al., 1991). To compare the effective absorption of gamma radiation, the mass absorption coefficient is used instead of particle absorption coefficient. The mass absorption coefficient is the absorption per density of the particle. As shown in Table $1, \mathrm{Zn}^{2+}$ had the highest mass absorption coefficient of $0.0364 \mathrm{~cm}^{2} \mathrm{~g}^{-1}$ while nickel had the lowest with $0.0110 \mathrm{~cm}^{2} \mathrm{~g}^{-1}$. The sedimentation constants correlate linearly with both particle absorption coefficients and mass absorption coefficients $(r>0.9956)$ as shown in figure 2. This suggests that sedimentation rates are higher for particles having higher mass absorption (or particle absorption) coefficient. 


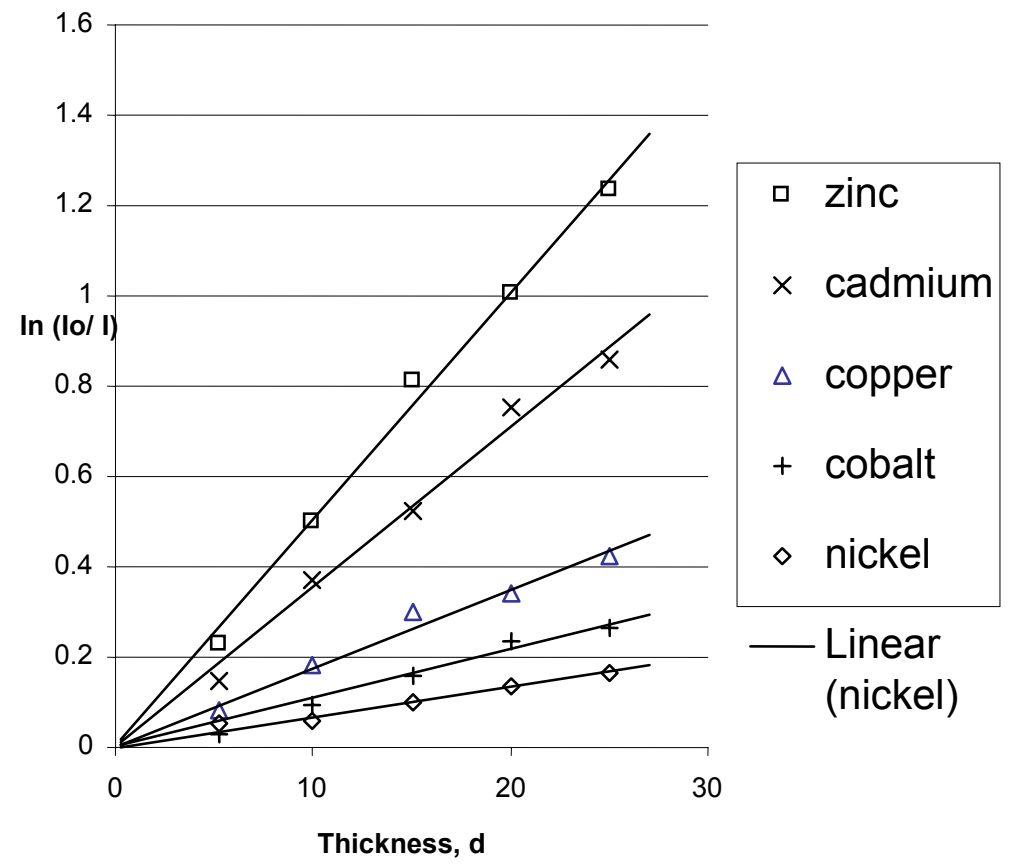

Fig. 1: Variation in absorption of gamma radiation with thickness of metal carbonates.

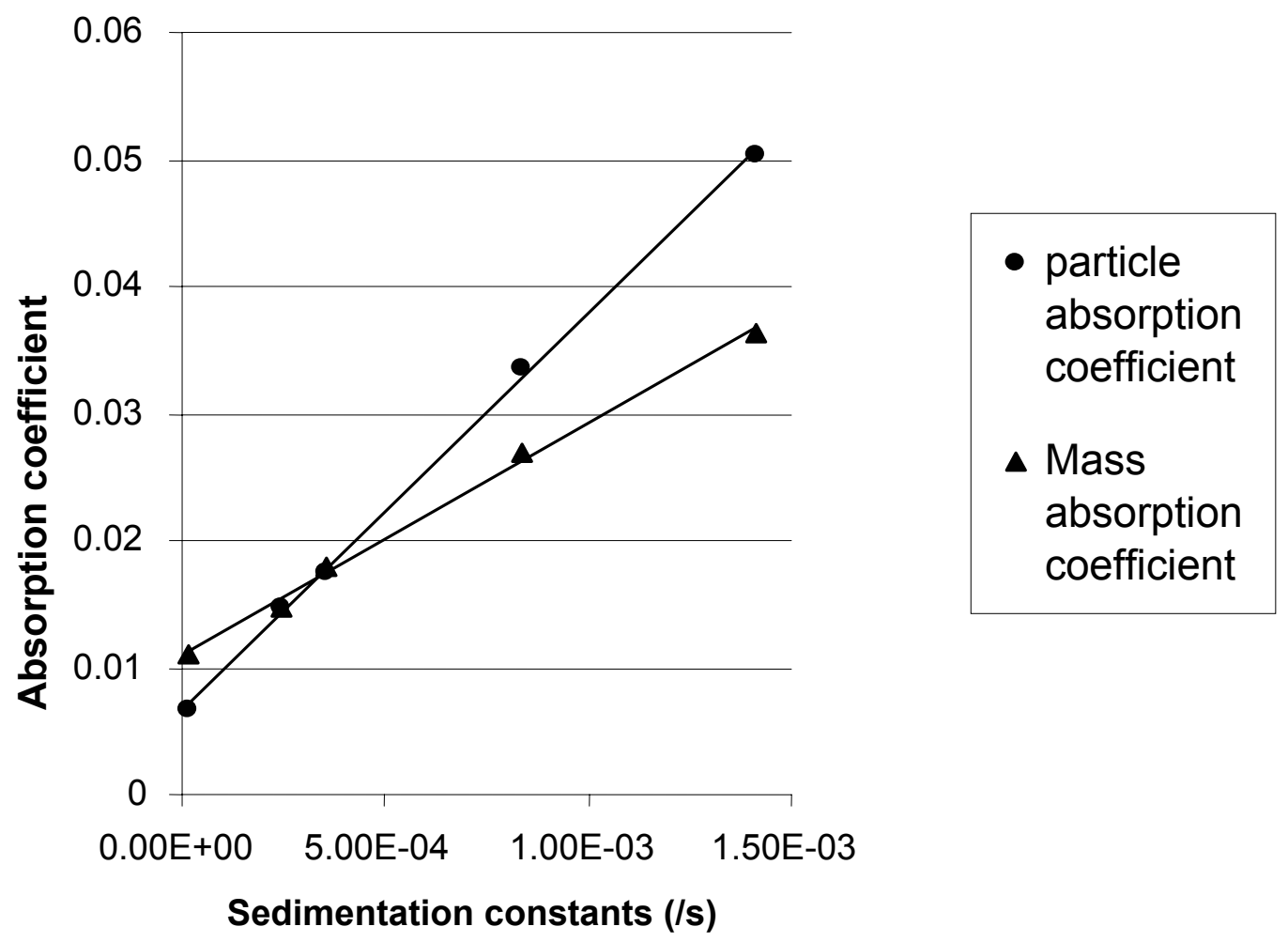

Fig. 2: Dependence of absorption coefficients on sedimentation constants 
In conclusion, the rates of sedimentation of insoluble metal carbonates have been determined by method involving the free settling of the carbonates under gravity. $\mathrm{ZnCO}_{3}$ with a higher density shows higher sedimentation rate and mass absorption coefficient. The mass absorption coefficients and sedimentation rates have been found to follow the order: $\mathrm{Zn}^{2+}>\mathrm{Cd}^{2+}$ $>\mathrm{Cu}^{2+}>\mathrm{Co}^{2+}>\mathrm{Ni}^{2+}$. The order shows a decrease in the density of the metal carbonates.

Acknowledgement: I am grateful to the Central Research Laboratory of the University of Uyo for providing the facilities needed for this work.

\section{REFERENCES}

Atkins, P W (1994). Physical Chemistry. Oxford University Press, London.

Essien, I O (1992). Studies on sedimentation rates of transition metal hydroxides. Tropical J Appl Sci 2:122-125.

Essien, I O; Ekpe, S D (1998). Determination of sedimentation rates of cobalt(II) insoluble compounds and absorption coefficient of the sedimenting particles using gamma radiation. $\mathrm{J}$ Chem Soc Park 20:120-124.
Gardner, W H; Jury, W A; Gardner, W R (1991). Soil Physics. John Wiley and Sons, New York.

Gerland, S; Villinger, H (1995). Nondestructive density determination on marine sediment cores from gamma-ray attenuation measurements. Geomarine Letters 15(2):111-118.

Lieser, K H (1997). Nuclear and Radiochemistry: Fundamentals and Applications. John Wiley and Sons, New York.

Shaw, D J (1992). Introduction to Colloids and Surface Chemistry, $4^{\text {th }}$ ed. ButterworthHeinemann Ltd, Jordan Hill, Oxford.

Vaz, C M P; Oliveira, J C M; Reichardt, K; Crestana, S; Cruvinel, P E; Bacchi, O O S (1992). Soil mechanical analysis through gamma ray attenuation. Soil Technology 5:319-325. 